\title{
Methods to Evaluate the Success of Company Short- term Stock Investment Under the Accounting Standards in 2006 in China and Improvements Under the Accounting Standards in 2017
}

\author{
Yu Liu \\ Dalian Neusoft University of Information \\ Dalian, China
}

\begin{abstract}
An increasing number of listed companies conduct short-term stock investments in the A-share market in China nowadays. There is a need to evaluate whether these companies have succeeded in the stock investments. However, how to measure the success of such investments comes into question. To evaluate the stock investment effects, three methods are discussed and evaluated in this essay. When the investment successes are measured, the different treatments for unrealized income under the accounting standards in 2006 in China bring difficulties for selecting measures for the investment evaluation. A change in the accounting standards in 2017 has been made to tackle the problems.
\end{abstract}

Keywords-company security investment; trading financial assets; available-for-sale financial assets; investment income; unrealized income; realized income

\section{INTRODUCTION}

In the Chinese A-share stock market, an increasing number of publicly listed companies engage heavily in investing in other A-share stocks nowadays. Some investments are for long-term strategic merger and acquisition purpose, while other stocks are invested for short-time purpose. According to the accounting standards in 2006 in China, short-time stock investments should be recorded in the account of trading financial assets. However, short-time stock investments can also be recorded as available-for-sale financial assets in the balance sheet for earning management purpose [1]. Therefore, both trading financial assets and available-for-sale financial assets are analyzed to study short-time stock investment. Besides, companies may invest in stocks directly or indirectly through funds and other financial products, so security investment is often used to illustrate the investment behavior. Short-time security investment is emphasized in this essay.

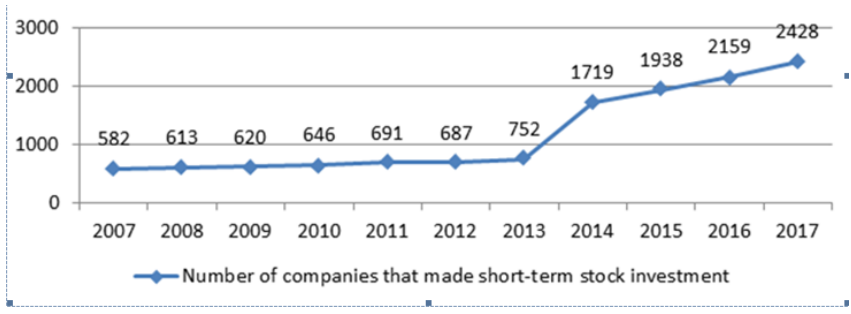

Fig. 1. Number of companies making short-term stock investment from 2007 to 2017.

Based on the data in CSMAR which is summarized in "Fig. 1", in 2007, about 582 non-financial companies in the A-share market conducted short-time security investment. An increasing number of listed companies invested in securities recently. In 2017, approximate 2428 non-financial companies in the A-share market invested in other A-share company's securities. As shown in "Fig. 2", in 2017, around 228 listed companies in the A-share market made short-term stock investments no smaller than $10 \%$ of their total assets. Although the majority of the companies in the A-share market invested less than $5 \%$ of the companies' total assets in the short-term stock, there are non-financial listed companies investing above $50 \%$ of their total assets in securities in 2017.

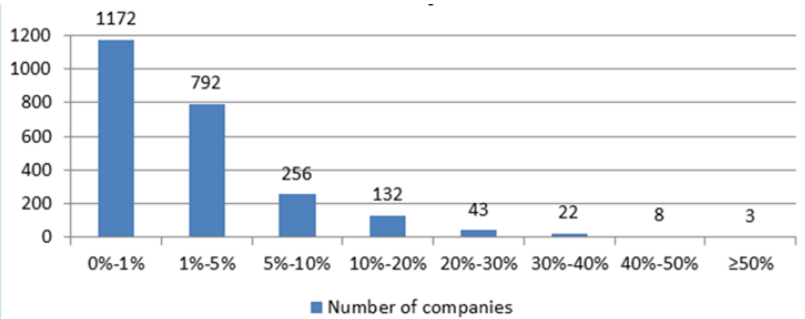

Fig. 2. Stock investment proportion of total asset comparison in 2017.

Taking Shanghai RAAS (ticker: 002252) for example. Shanghai RAAS Blood Products Company was established in 1988 and was publicly listed on the Shenzhen Stock Exchange in 2008. Shanghai RAAS specializes in the 
research, development and manufacturing of blood products. However, in 2015, the company decided to invest no more than 1 billion in venture in 2 years, and the fund was then invested in the stock market. The upper investment limit was extended to 4 billion in 2016 [2]. Nevertheless, Shanghai RAAS suffered greatly from the stock investment in 2018 and raised the public awareness. The company was reported to lose about 1.98 billion mainly due to stock speculation in 2018 [3], when the profits from its main business of blood products actually increased during the same period.

When the investments in the stock market were increasing, did the companies making these investments succeed in the short-time securities investment? There is a need to evaluate the success of the security investments. However, how to measure the success of such investments comes into question. To evaluate the security investment effects, the following three methods are discussed and evaluated.

\section{Methods to Evaluate the Security InVESTMENT SUCCESS}

\section{A. Using the Absolute Value of the Incomes Recognized in $P \& L$}

According to the accounting standards in 2006, shorttime stock investments can be regarded as either trading financial assets or available-for-sale financial assets in the balance sheet [1]. Stocks are measured under fair value basis except some stocks whose fair values cannot be measured precisely in the available-for-sale financial asset account. The incomes from short-time stock investments are divided into two parts, the realized income and the unrealized income. When the invested stock's value increases and the stock is sold out, the increased value becomes realized income which is recorded in the account of investment income on the income statement. Realized incomes from both trading financial assets and available-for-sale financial assets are recognized as profits, according to the accounting standards 2006. As for what is unrealized income, if the invested stock is retained rather than sold out by the investor company, the increased value of the stock is credited to the unrealized income of the stock. When the invested stock is sold out, the unrealized income becomes realized income.

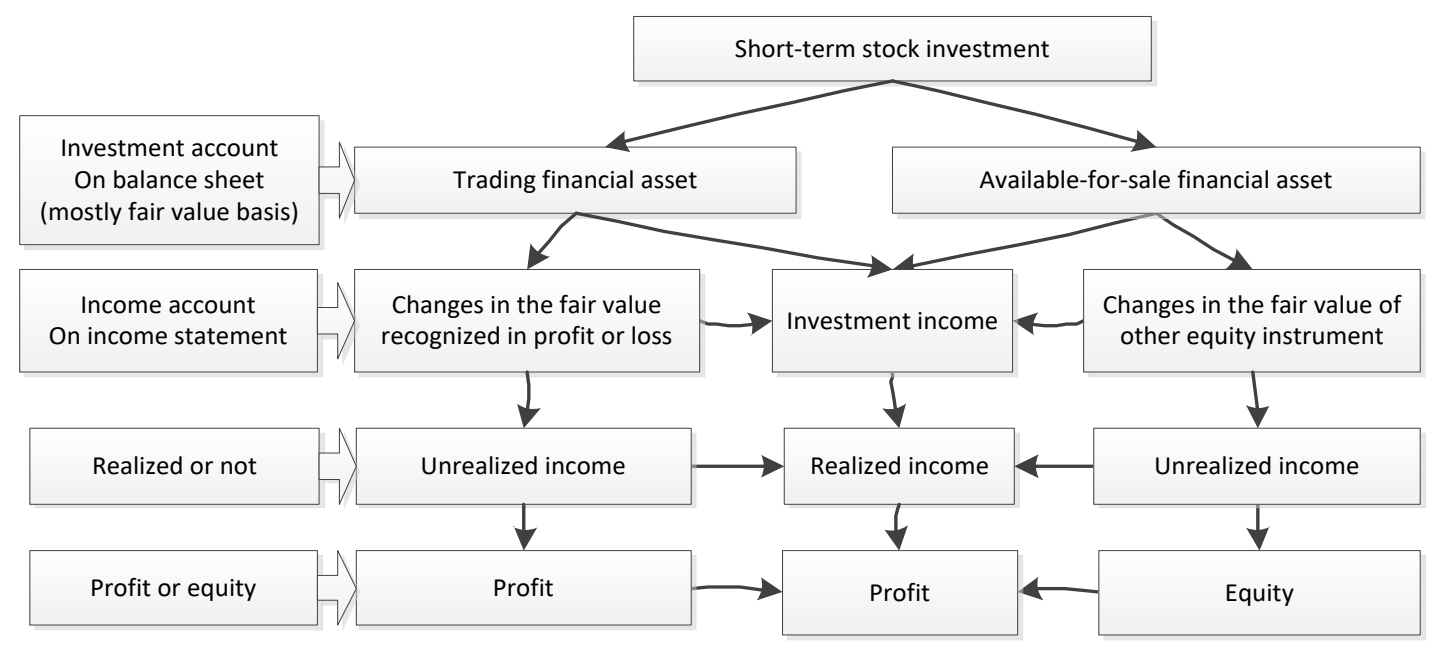

Fig. 3. Different treatments for unrealized income.

As shown in "Fig. 3", for companies doing the stock investment, unrealized incomes from the two asset investment accounts are treated differently. Unrealized income from trading financial assets is an increase in the account of changes in the fair value recognized in profit or loss, and the increase is regarded as a type of profit. In contrast, unrealized income from the account of availablefor-sale financial assets is an increase in the account of changes in the fair value of other equity instruments, and the increase is treated as a type of equity rather than profit. In other words, the unrealized income of an invested stock can be recorded as either a profit or equity, depending on which asset account the invested stock is put in.

As discussed in the background information, a company can treat its stock investment as either trading financial assets or available-for-sale financial assets, based on the company's own judgment. If a company puts its stock investment in the account of available-for-sale financial assets, the company can conduct earnings management according to Wu Zhanchi [1]. Specifically, a company can hide the unrealized income from the available-for-sale financial assets in the equity. When the company needs to increase its profit, the company can sell some stocks with good performance and move the unrealized income from equity to profit [1]. In contrast, when the company needs to lower its profit, the company can sell some stock with bad performance to decrease the realized profit [1]. In other words, a company has the ability to manipulate its profits [1] or smooth its profits [4] under accounting standards 2006. The company can decide when and how much the invested stock appear to profit in the income statement. Therefore, the absolute value of related income changes in the P\&L is inappropriate to be used to evaluate the success of stock 
investments. If the method is used, the evaluation results lack objectivity.

\section{B. Using Realized Income and Excluding the Unrealized Income}

Based on the discussions above, the accounting standards in 2006 treat the unrealized incomes from different investment accounts on the balance sheet in different ways. In the previous studies on security investment, such as one study by Wu Zhanchi [1], only the unrealized income from the trading financial assets, which is recognized as profit, is considered to evaluate stock investments, but unrealized income from the available-for-sale financial assets is ignored in evaluation, based on the accounting standards treatment difference.

However, to evaluate stock investment success, it is inappropriate to treat unrealized income differently. If both the trading financial assets and the available-for-sale financial assets are regarded as company stock investments, it is unreasonable to regard unrealized income from trading financial assets as a type of investment return and disregard unrealized income from the available-for-sale financial assets at the same time. If one-part of the unrealized income is disregarded, the total investment return is undervalued on the condition.

A solution to tackle the problem above is to include the unrealized income from the available-for-sale financial assets as well, to evaluate the stock investment effects. Both realized income and unrealized income from the two investment accounts are treated as investment return from stock investment in this way. However, unrealized income from the available-for-sale financial assets is treated as equity rather than profit on the income statement, according to accounting standards 2006. Investors evaluate information from equity and profit in different ways. If unrealized incomes from equity and profit are added together directly, the unrealized incomes from equity and profit are treated to be of equal importance to the investors, making the treatment go against the reality.

Based on the discussions above, the difference in the treatment of unrealized income under accounting standards in 2006 brings difficulties, when the successes of stock investments are analyzed. However, since the unrealized income is not realized and not real then, the unrealized income perhaps can be considered separately to some extent to evaluate stock investment effects. This is also how some previous research on security investment analyzed the return from the investments [5]. Then using only the realized investment income from the income statement to evaluate the effects may be relatively appropriate in a sense. Admittedly, if only realized incomes are considered to evaluate the success of stock investment, the total income from the investment is still undervalued. The realized income recognized as the profit is open to manipulation, too.

\section{Using the Rate of Return on Company Stock Investment}

\section{1) The establishment of the ratio}

Even though only the realized income is considered, eliminating effects from different treatments of unrealized incomes, there are still other special characteristics to consider in evaluation of stock investment success. To analyze the performance of an asset investment, the ratio of return on the assets is usually calculated, because the rate of return can be used to compare the performances of assets of different scales. To calculate the rate of return on short-term stock investment, only the realized income is used as the numerator of the ratio. The unrealized income is currently excluded from the numerator, to eliminate the effects from the accounting standards' different treatments of unrealized incomes from similar short-term stock investments.

Rate of return:

$$
\text { rate of return }=\frac{\text { investment income }}{\text { trading financial asset }+ \text { available }- \text { for }- \text { sale fianncial assets }}
$$

The formula of the rate of return is shown in the formula above. The return on stock investment equals to the investment income from the trading financial assets and available-for-sale financial assets divided by the sum of these two assets. In this formula of rate of return, the realized income is the numerator. The problem is whether the fair value of the invested stocks or the historical value of them is the denominator. Both conditions are discussed as below.

2) Using the fair value of the invested stocks as the denominator

In the formula of the rate of return, if the realized income is the numerator, the fair value of the invested stocks is the denominator, as shown in the following formula "Rate of return (fair value) 1". In other words, the denominator includes both the historical invested value of the stock and the unrealized increased value of the stock, as shown in the following formula "Rate of return (fair value) 2".

Rate of return (fair value) 1:

$$
\text { rate of return }=\frac{\text { investment income }}{\text { fair value }}
$$

Rate of return (fair value) 2 :

$$
\text { rate of return }=\frac{\text { investment income }}{\text { historical value }+ \text { unrealized value }}
$$

In this case, when the price of the invested stock increases, and if the company sells the stock, the numerator increases and the denominator decreases. Consequently, the rate of return on the stock investment increases. By contrast, when the price of the invested stock increases, and if the company retains the stock rather than sells it out, the numerator of the ratio remains unchanged but the denominator increases. Consequently, the rate of return on the stock investment decreases. In other words, when the invested stock's price increases and the investment seems successful, the rate of return on the stock investment declines to show the investment is unfavorable. The ratio fails to evaluate the investment success, if the fair value of the invested stock is used as the denominator. Besides, the 
investor company can manipulate the return ratio to conduct earnings management by retaining or selling stock behavior.

3) Using the historical invested value of the stocks as the denominator

In the formula of "Rate of return (historical value)", if the realized income is the numerator, the historical invested value of the stocks is the denominator. In other words, the denominator excludes the unrealized increased value of the stock.

\section{Rate of return (historical value):

$$
\text { rate of return }=\frac{\text { investment income }}{\text { historical value }}
$$

In this case, when the price of the invested stock increases, and if the company sells the stock, the numerator increases and the denominator is unchanged, making the rate of return on stock investment increase. By contrast, when the stock price increases, and if the company retains the stock rather than sells it, both the numerator and the denominator are unchanged, so the ratio remains constant. In other words, the ratio does not reflect the success of the investment either, when the stock price increases and the investment is successful. Moreover, the investor company can still manipulate the ratio by retaining or selling behavior.

\section{4) Indications from the use of the ratio}

Based on the discussions in the paragraphs above, two conclusions can be drawn. First, when the invested stock's price increases, the rate of return on short-term stock investment may not reflect the success of the investment, no matter the denominator is the fair value or the historical value of the invested stock. Therefore, the rate of return on stock investment itself cannot always judge whether the company succeeds in the investment correctly. Second, the investor company can choose to sell or retain the stock to manipulate the changes of the rate of return on stock investment. In other words, the return ratio can be changed by the company's retain-or-sell decision, rather than by the stock price changes. The changes of the return ratio lack objectivity. Therefore, the rate of return is inappropriate to evaluate the success of stock investment objectively under accounting standards 2006.

\section{Summary for Methods Under Accounting Standards 2006}

To summarize, when only the realized income is used as the numerator to calculate the rate of return on short-term stock investment, the return ratio is inappropriate to evaluate the success of stock investment. However, if both the realized income and the unrealized income are considered, the accounting standards' different treatments on unrealized income from trading financial assets and available-for-sale financial assets cause trouble to establish the formula ratio. Consequently, none of the three methods discussed above is a proper way to evaluate the success of stock investment under accounting standards 2006.

\section{IMPROVEMENTS UNDER ACCOUNTING STANDARDS 2017}

\section{A. Improvements from the Standards Change}

Improvements have been made in the accounting standards in 2017. First, stock investment is classified due to business pattern and cash flows rather than management purpose. According to Recognition and Measurement of Financial Instruments in Accounting Standard 22 for Enterprises in 2006 [7], short-time stock investment is recognized as either trading financial assets or available-forsale financial assets, depending on management investment purpose and intention. According to Recognition and Measurement of Financial Instruments in Accounting Standard 22 for Enterprises in 2017 [8], the short-term stock investments need to be reclassified into two types, named "financial assets measured at fair value whose changes are included in current profits and losses", and "financial assets measured at fair value whose changes are included in other comprehensive income" respectively. The classification depends on the invested business' pattern and the features of the cash flows from the financial instrument objectively, rather than on the management intention subjectively.

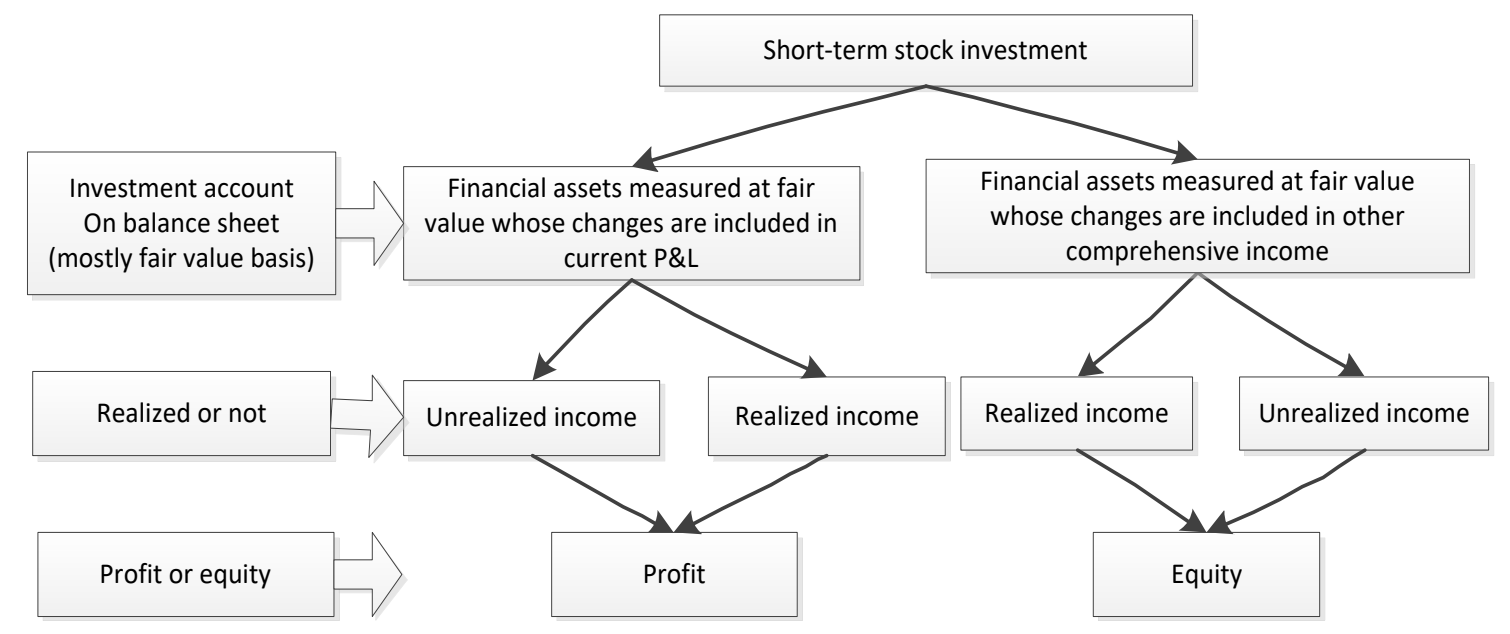

Fig. 4. Improvement on unrealized income treatment in 2017 
Second, the problem of different treatments for unrealized income is solved. As shown in "Fig. 4", if the stock investment is classified into financial assets measured at fair value whose changes are included in current profits and losses, the realized and unrealized income from this stock investment are both recognized in the profits and losses. If the stock investment is classified into financial assets measured at fair value whose changes are included in other comprehensive income, the realized and unrealized income from the stock are both recognized in the equity. In other words, no matter the income is realized or unrealized, the income from one stock investment is always recognized as profits or as equity, depending on which asset account the investment belongs to. A company can hardly conduct earnings management through retain-or-sell decision, as the unrealized and realized incomes are treated and recognized equally in the income statement.

\section{B. Effects of the Improvements}

The improvement in the accounting standards is favorable to evaluate the stock investment success. The formula of rate of investment return can be revised to be more reasonable than before. If a stock investment is classified into financial assets measured at fair value whose changes are included in current profits and losses, both the realized and the unrealized income from the investment become the numerator of the ratio, and the historical invested value of the asset becomes the denominator, as shown in formula "Rate of return 2017". When the invested stock price increases, the ratio increases, no matter the company retains or sells the stock. To compare, if a stock investment is classified into financial assets measured at fair value whose changes are included in other comprehensive income, the numerator also includes all the incomes from the other comprehensive income statement, and the denominator is the historical value. The return ratio changes correctly with the stock prices in this case as well. The new return ratio is reasonable and practical.

Rate of return 2017:

$$
\text { rate of return }=\frac{\text { realized }+ \text { unrealized income }}{\text { historical value }}
$$

\section{CONCLUSION}

Based on the discussions above, when the short-term stock investment successes are measured, the different treatments for unrealized income under the accounting standards 2006 in China bring difficulties for selecting measures for the investment evaluation. The revised accounting standards in 2017 solved the problem of different treatments for unrealized income in accounting standards 2006. Under the new accounting standards, the formula ratio of investment return becomes more practical and reasonable to evaluate stock investment success. The revised standards are put into practice from 2018 step by step, and company stock investment successes can be analyzed in a proper way since then. However, how to evaluate the successes of shorttime company stock investments in Chinese A-share market from 2007 to 2017 properly, during which period accounting standards 2006 were in practice, is still in question.

\section{REFERENCES}

[1] Wu Zhanchi, Luo Shaode and Wang Wei, 2009, The Research on Value Relevance and Earnings Management of Securities Gains and Losses [J]. Accounting Research 6, 42-49+97.

[2] Annual financial report of Shanghai RAAS (2017), retrived from http://www.raascorp.com/upload/20180510103516fj_groupcopy1.pdf

[3] Preliminary earnings estimates of Shanghai RAAS (2018), retrived from.

http://data.eastmoney.com/notices/detail/002252/AN2019022713005 57489,JWU0JWI4JThhJWU2JWI1JWI3JWU4JTh1JWIxJWU1JWEz JWFi.html.

[4] Han Yan, Cui Xin and Guo Yan, 2015, A Study on the Motives of the Chinese Listed Firm's Stock Investments [J]. Journal of Management Science 28(04), 120-131

[5] Wang Wei, 2010, The Securities Speculation of listed companies in China: Behavior Motivation and Economic Consequences [D] Southwestern University of Finance and Economics.

[6] Lu Junwei, Shi Xin and Han Fei, 2015, The Influencing Factors of Disclosure Quality of Investment Income in Listed CompaniesEmpirical Evidences from Shanghai and Shenzhen A-share Markets from 2009 to 2013 [J]. Finance Research, 2015(06): 64-73.

[7] Corporate accounting standard No.22- Recognition and Measurement of Financial Instruments in Accounting Standard 22 for Enterprises (2006), issued by Ministry of Finance of the People's Republic of China.

[8] Corporate accounting standard No.22- Recognition and Measurement of Financial Instruments in Accounting Standard 22 for Enterprises (2017), issued by Ministry of Finance of the People's Republic of China. 